\title{
Exploring the influence of technological support, cultural constructs, and social networks on online cross-cultural learning
}

\author{
Rustam Shadiev \\ Nanjing Normal University \\ Yueh-Min Huang
National Cheng Kung University
}

In this study, we carried out an online cross-cultural learning activity supported by speechenabled language translation technology on a social network service with representatives from 13 nationalities. The participants were assigned into two groups: Group I discussed the traditions and related culture of interest whereas Group II discussed traditions, culture, and any other topics of interest. We tested the effectiveness of the learning activity supported by speech-enabled language translation technology on cross-cultural learning; analysed the social network; measured the cultural constructs, and investigated the relationship between the cultural constructs and cross-cultural learning. The results revealed that Group I outperformed Group II in terms of both procedural and declarative knowledge. The results showed that Group II had better social network characteristics; for example, Group I had fewer edges and a lower average network degree than Group II. In terms of cultural constructs, the results related to power distance, individualism, and uncertainty avoidance were contradictory to those of earlier research. Finally, we found no relationship between the cultural constructs and cross-cultural learning. In this paper, we discuss implications for and suggestions to the field of technology-supported cross-cultural learning based on the results.

Implications for practice or policy:

- Educators need to know that content-focused communication among participants in a social network enhances cross-cultural learning, whereas social communication facilitates a strong social network.

- Educators need to maintain a balance between communication styles during learning activities in order to establish a strong social network and facilitate cross-cultural understanding.

- Educators need to consider in their cross-cultural learning design a contradiction between our results related to cultural constructs and those obtained in previous studies.

Keywords: cultural constructs, social network, cross-cultural understanding, speech-enabled language translation

\section{Introduction}

Cross-cultural understanding is the ability of individuals to connect with people from different cultures through a deeper sense of appreciation of those cultures (Shiraev \& Levy, 2015). Due to globalisation, cross-cultural understanding has become a very important issue (Uzun, 2015) because people are in close proximity, exposed to an increasing number of culturally diverse people and are encouraged to have a range of relationships (Aparicio, Bacao \& Oliveira, 2016). As a result, there is an increasing demand for competence in communicating and living peacefully among people with different cultural backgrounds (Lustig \& Koester, 2010). In order to be successful with regard to such communications, it is necessary to have knowledge of and respect for cultural differences and to further understand how they affect one's interaction skills and behaviour (McMurray, 2007).

Scholars have argued that communication and information exchange are the main components of crosscultural learning because they help people reach a mutual understanding of each other's culture (Yamazaki \& Kayes, 2004). People communicate and share experiences with and insights into other cultures, which leads to the expansion of their cultural awareness and behaviour (Gudykunst, Ting-Toomey, \& Chua, 
1988). However, scholars have warned that some issues in cross-cultural learning still exist and may hinder the learning process, among which the most challenging issue is the language gap (Osman \& Herring, 2007; Rienties, Johan, \& Jindal-Snape, 2015). When learners do not have a common language, it is difficult and may even be impossible to communicate and exchange information with others and thus develop crosscultural understanding. Application of speech-enabled language translation (SELT) technology has been proposed to overcome this issue (Shadiev \& Huang, 2016). Typically, SELT technology includes two tools: speech-to-text recognition (STR) and computer-aided translation (CAT). According to Shadiev and Sun (2019), the STR function of SELT receives speech input in one language and the CAT function of SELT simultaneously translates it into different language, making interaction among representatives of different cultures without a common language possible. Scholars have suggested that STR technology is a useful tool to aid students' learning in both physical (Ranchal et al., 2013) and cyber classrooms (Kuo, Shadiev, Hwang, \& Chen, 2012) in the case of non-native speakers (Ranchal et al., 2013) and students with cognitive or physical disabilities (Shadiev, Hwang, Chen, \& Huang, 2014). For example, students can focus on the lecture instead of taking class notes when lecture transcriptions are available in a physical classroom (Ranchal et al., 2013; Shadiev et al., 2014). In a cyber classroom, students can follow the lecturer by reading STR texts when network connections are not stable and they cannot hear the lecturer (Kuo et al., 2012). During lectures in a foreign language, students can listen to the lecturer and simultaneously read STR texts to understand unfamiliar words and to verify or clarify words they have misheard (Ryba, McIvor, Shakir, \& Paez, 2006; Shadiev et al., 2014). CAT technology has great potential to aid second or foreign language (SL or FL) learning (ElShiekh, 2012; Hermet \& Désilets, 2009) and cross-cultural understanding (Shadiev \& Huang, 2016). Students have composed essays in SL or FL writing activities and then corrected any grammatical and lexical errors using CAT (ElShiekh, 2012; Hermet \& Désilets, 2009). Students in Shadiev and Huang's (2016) study were from two different cultures, and they used STR and CAT for bilingual communication and information exchange.

Communication is an essential aspect of culture (Gugel, 2017). According to Matveev and Milter (2004), communication can be divided into different styles, that is, focused communication and social communication. The former is characterised by assertive, directive, and instrumental output, such as directive statements and information provision, as well as critical evaluation of contributions. The latter is affiliative and includes expressions of support, agreement, and acknowledgment of the contributions of others (Iosub, Laniado, Castillo, Morell, \& Kaltenbrunner, 2014). Misiolek, Crowston, and Seymour (2012) suggested that focused communication relates more to decision-making and problem-solving. That is, participants actively discuss and critically examine the contributions of others. Social communication is not concerned with a task, nor is it essential for the direct fulfilment of tasks. Ogbu (1992) argued that communication styles affect cross-cultural learning. Following this notion, Matveev and Milter (2004) suggested that differences in communication styles influence learning dynamics and the ability of people to achieve high levels of performance. Our literature review revealed that few studies have explored the impact of communication styles on cross-cultural learning. Therefore, in our study, we aimed towards bridging this gap in the literature. To this end, we attempted to explore how communication styles affect cross-cultural learning.

Cross-cultural interaction and information exchange among people from different locations can be supported by various communication technologies (Osman \& Herring, 2007). Çiftçi (2016) found that social networking services, such as online discussion boards, text-based chatting, and blogs, are technologies frequently used to aid cross-cultural learning because social network services facilitate communication, social interactions, and coordination among distributed learners. A social network is defined as a social structure made up of a group of individuals who are not co-located but rather are connected by social relations such as friendship, cooperation, or information exchange (Garton, Haythornthwaite, \& Wellman, 1997). Mitchell (2012) suggested that people join social networking sites (SNSs) to communicate with existing friends, to gain perceived benefits to their social life, and to obtain learning benefits. Individuals interacting on SNSs are interdependent, so their needs and goals cause them to influence each other (Aronson, Wilson, Akert, \& Sommers, 2016). Social network analysis theory states that social relationships can be regarded in terms of nodes and edges, where nodes represent individuals who constitute a social network, and edges are the relationships among these individuals (HernándezGarcía, González-González, Jiménez-Zarco, \& Chaparro-Peláez, 2015). Nodes can be connected with one another by many types of edges, so a social network can be presented as a map with relevant edges among nodes (Hernández-García et al., 2015). Granovetter (1983) claimed that the strength of social ties in a social network depends on the amount of time individuals have known each other, as well as the degree of 
emotional intensity, intimacy, and reciprocal services that exist among individuals. Gilbert and Karahalios (2009) proposed two more factors that influence the strength of social ties: emotional support and social distance. For example, social ties are stronger among individuals who share similar demographics, for example, ethnicity, age, religion, occupation, and gender (Feld, 1981; McPherson, Smith-Lovin, \& Cook, 2001), and it is more likely that students will have stronger friendships with those who are taking the same classes, whereas weak ties will tend to exist between individuals with specific, limited information exchange (Shrum, Cheek, \& Hunter, 1988).

Social networks significantly influence learning performance in collaborative settings because learning activities in such environments are primarily based on communication, social interactions, and coordination among distributed learners (McPherson et al., 2001). Therefore, it is important to analyse social networks in order to explore direct or indirect connections between a person or a group to other individuals or groups (Chen \& Chang, 2014; Gilbert \& Karahalios, 2009). A social network analysis focuses on analysing patterns of relationships among people, organisations, states, and individuals (Granovetter, 1983). Several scholars have explored the usage of SNSs for cross-cultural learning. For example, Mitchell (2012) carried out a qualitative case study with seven ESOL students to explore their motivations for joining SNSs. Walsh, Brown, and Druin (2011) analysed an online social network intended to foster cross-cultural awareness among users. Rienties et al. (2015) explored how international and host university students develop social learning relationships.

Our review of the literature on cross-cultural learning showed that little attention has been paid to analyses of social networks, specifically their characteristics (e.g., nodes and edges). There are several important characteristics of social networks. In this study, we analysed how social network characteristics differ across different communication styles (i.e., focused communication and social communication).

One important aspect of cross-cultural learning is cultural constructs. Several researchers have claimed that various cultural factors underlie human behaviour. For example, Adams, Rodriguez, and Zimmer (2018) and Hofstede (1986) argued that cultural differences between instructors and students impact their teaching and learning, respectively. Strang (2010) suggested that the academic performance of students can be predicted based on their learning style and cultural characteristics. Bozkurt and Akbulut (2019) explored dropout patterns and cultural contexts in online networked learning spaces. Their social network analysis showed that students from highly cultural contexts (e.g., interaction is based on non-verbal cues and building relationships that develop slowly, have strong visible boundaries, and last longer) tend to drop out, whereas those from low cultural contexts (e.g., communicate explicitly and build relationships that develop quickly, have more flexible boundaries, and are shorter). Hofstede (2001) proposed the cultural constructs theory to describe the effects of a specific culture on the values of its representatives and how these values relate to their behaviour. That is, the theory seeks to explain observed differences between cultures in terms of the following constructs: (a) power distance, defined as the extent to which the less powerful members of organisations and institutions accept and expect that power is distributed unequally; (b) individualism, defined as the degree to which people in a society are integrated into groups; (c) uncertainty avoidance, defined as a society's tolerance for ambiguity; and (d) masculinity, defined as a preference in society for achievement, heroism, assertiveness, and material rewards as representing success (Hofstede, 1991). The scores for each dimension make it possible to make comparisons between cultures. For example, the scores for the power distance construct are very high for Asian countries but are very low for western European countries. Our literature review on cross-cultural learning also showed that not much attention has been paid to analyses of cultural constructs. It is important to analyse cultural constructs because their characteristics may affect cross-cultural learning. Therefore, we measured the perceptions of our participants towards cultural constructs. We also investigated the relationship between cultural constructs and cross-cultural learning. We addressed the following research questions in this study:

(1) Is a learning activity supported by SELT beneficial for cross-cultural learning and how do learning outcomes differ across two communication styles?

(2) What social networks are the students using and how do their characteristics differ across two communication styles?

(3) What are the students' perceptions of the social networks and how do they differ across two communication styles?

(4) What are the students' perceived cultural constructs and how do they correlate with learning outcomes? 


\section{Method}

We chose a mixed research method for this study to collect data from multiple sources: a learning performance analysis, a social network analysis, two questionnaires, and interviews. We employed experimental, correlational, and descriptive research designs. That is, we compared the results related to learning performance, social network, and student perceptions across two groups. In addition, we calculated the relationship between learning outcomes and cultural constructs. Furthermore, we used interview data to support and explain findings of this study.

\section{Sample and procedure}

Twenty-one university students representing 13 nationalities participated in our study; the nationalities were Belizean, Burkinabe, Honduran, Indian, Indonesian, Mexican, Mongolian, Panamanian, Paraguayan, Filipino, Chinese, Uzbekistani, and Vietnamese.

The study took place during the Spring semester of 2016 in Taiwan. We distributed consent forms among the participants at the beginning of the study. The forms informed them about purpose of the study and provided details about their participation. The participants signed the forms and returned them to us. Then, we collected demographic information on the participants using a questionnaire, after which the instructor informed the participants about the learning activity. We trained the participants on how to use SELT. Next, the participants participated in the learning activity. After the learning activity, we evaluated the crosscultural understanding of the participants and surveyed their perceptions of the usefulness of a social network and cultural construct using a questionnaire. In addition, we analysed the communication content and the social networks of the participants and carried out one-on-one semi-structured interviews with them.

All procedures performed in this study were in accordance with the ethical standards of the institutional research committee. Informed consent was obtained from all individual participants included in the study.

\section{Research design}

The cross-cultural learning activity consisted of the following steps: (a) Self-introduction: We asked the participants to introduce themselves; (b) Introducing local traditions: We asked the participants to introduce their local traditions and related culture; (c) Experiencing foreign traditions: We asked the participants to select one tradition, to experience it, and then to share their personal experience of the foreign tradition and related culture with the other participants; (d) Sharing experiences: We asked the participants to communicate with each other about themselves, their traditions, and their experiences with foreign traditions and related cultures. Each of the first three steps lasted for 1 week, and the last step lasted for about 2 hours. The participants communicated in a closed Facebook group during the first three steps and via Skype during the fourth step. Communication was asynchronous through text messages and pictures in the Facebook group, and it was synchronous through text messages, pictures, voice, and video via Skype.

We employed SELT technology to support communication and information exchange among the participants. In this study, the Google $\AA$ Translate system was employed as the SELT technology because it includes both STR and CAT tools. Google ${ }^{\circledR}$ Translate is an automated machine translator application that offers free online language translation service to users with internet access. It can be used to translate words or phrases from one language into another and supports more than 100 languages. The algorithms for Google ${ }^{\circledR}$ Translate are not rule-based as is the case with most CAT systems but rather are based on statistical analyses (Tobin, 2015). That is, it relies on a large corpus of professionally translated texts and looks for equivalences (Fountain \& Fountain, 2009).

We randomly divided the participants into two groups. In Group I, every participant interacted only with one member of the group, i.e. with a person whose tradition and culture a given participant chose to learn and experience, so the communication was limited to a discussion of a tradition and culture of interest. In Group II, every participant interacted with any member of the group, and the interaction was not limited to a tradition and culture a participant chose to learn and experience. Thus, communication style was different for each group - focused communication for Group I and social communication for Group II (Iosub et al., 2014; Matveev \& Milter, 2004; Misiolek et al., 2012). This division was planned in advance of the 
experiment, and the participants were allocated to a group. We instructed the participants in Group I and Group II about the communication style that differentiated them and asked the participants in Group I to interact with a partner about a tradition and culture of interest only, whereas the participants in Group II were asked to interact with more than one person about a tradition and culture of interest as well as other interesting topics.

\section{Data collection}

We collected the data from different sources using the following instruments:

- Evaluation of cross-cultural understanding - We evaluated cross-cultural understanding in terms of procedural (knowing how to perform certain activities) and declarative (factual knowledge and information that a person knows) knowledge.

- Social network analysis - We employed Gephi, an open-source network analysis and visualisation software package.

- Perceptions of the usefulness of a social network - We employed a questionnaire survey (Shadiev $\&$ Huang, 2016) to measure the perceptions of the participants related to the usefulness of social networks for cross-cultural learning.

- Hofstede's $(1983,2011)$ model - We used this model to measure cultural constructs.

- Interviews - One-on-one semi-structured interviews with all students were carried out after the learning activity in order to explore possible explanations for the findings of this study. The general recommendations of Creswell (2014) were considered for carrying out the interviews and the data collection. Each interview took approximately 30 minutes. A researcher (one of the authors) asked the participants about their learning and SELT usage experiences during the activity. The participants were also asked to share their perceptions regarding the usefulness of the activity supported by SELT and the social network in fostering their cross-cultural learning.

\section{Data analysis}

Cross-cultural understanding was measured on a 5-point Likert scale, where 5 was excellent and 1 was poor. To measure student procedural and declarative cross-cultural understanding, the content of the online communication of the students during the learning activity was analysed. To this end, a coding unit concept was adopted. That is, text segments representing the cross-cultural understanding of the participants were highlighted and coded. Codes with related meanings were then collected and grouped. Established groups of codes produced a framework for reporting the research findings. Three raters were involved in the scoring process. They resolved differences in the scores through discussion and by consensus.

For the social network analysis, the following characteristics of social networks were explored:

- Nodes - the number of participants

- $\quad$ Edges - the connections (through communication) between nodes

- Social category - social communication instances among the nodes

- Cognitive category - cognitive communication instances among the nodes

- Average degree - average number of ties an individual has to other individuals in the network

- Diameter - the number of edges of the longest path between any pair of nodes in the graph

- Average path length - the average number of edges along the shortest paths for all possible pairs of network nodes and used to measure the efficiency of information on a network

- Density - the ratio of the number of edges and the number of possible edges showing how well connected a network is.

Following the general recommendations of Shadiev and Huang (2016) and Hofstede (1983, 2011), the students provided their perceptions of the usefulness of a social network and answered the cultural construct questionnaires items on a 5-point Likert scale with the end points anchored as 1 (strongly disagree) and 5 (strongly agree).

The general recommendations of Creswell (2014) were considered for the analysis of the interview data. All interviews were audio-recorded and transcribed. The researcher and two assistants separately coded the 
text segments that contained information related to the research focus, aggregated codes with similar meanings, and then formed categories to produce a framework with which to report the results. Differences in the coding and categorisation were resolved through discussion until a consensus was reached. The interrater reliability was evaluated, and the result was high $(\alpha>0.85)$.

\section{Results}

The cross-cultural learning assessment results are presented in Table 1. Two examples showing the procedural and declarative knowledge of two participants are included in Appendix A. Both participants were able to explain foreign traditions and related cultures (declarative knowledge) as well as how the traditions can be carried out (procedural knowledge). We compared the procedural and declarative knowledge of the participants in the two groups. First, we carried out a multivariate analysis of variance to explore whether the two groups differed overall. According to the results, there was a statistically significant difference in learning performance based on the communication styles of the participants in both groups, $F(2,18)=7.253, p<0.005$; Wilk's $\Lambda=0.554$, partial $\eta 2=.446$. Next, an independent $t$ test was used to assess the between-group differences in the procedural and declarative knowledge. Our statistical results showed that Group I $(M=4.82 ; S D=0.60)$ outperformed Group II $(M=4.00 ; S D=0.67)$ in terms of procedural knowledge $(t=2.954, p<0.05)$. According to the results, Group I $(M=4.45 ; S D=0.69)$ outperformed Group II $(M=3.70 ; S D=0.67)$ in terms of declarative knowledge as well $(t=2534, p<$ $0.05)$.

Table 1

T test results for the between-group comparison of procedural and declarative knowledge

\begin{tabular}{llllll}
\hline Evaluation scores/Group & Mean & Standard deviation & $t$ & $p$ & $d$ \\
\hline Procedural knowledge & & & & & \\
I & 4.82 & 0.60 & 2.954 & 0.008 & 1.29 \\
II & 4.00 & 0.67 & & & \\
Declarative knowledge & & & 2.534 & 0.020 & 1.10 \\
$\quad$ I & 4.45 & 0.69 & & & \\
II & 3.70 & 0.67 &
\end{tabular}

The results of the social network analysis for the two groups are presented in Table 2. Figure 1 shows the social networks of the two groups. The social network of Group I had 12 nodes and 248 edges. This network had an average degree of 20.667 and a diameter of 3 . The average path length of the network was 1.36 , and the density was 0.629 . The social network of Group II had 11 nodes and 397 edges. The network average degree was 36.091, and the diameter was 2 . The network had an average path length of 1.12 and a density of 0.955 . Although both groups had almost the same number of nodes, Group I had fewer edges than Group II.

Table 2

Results related to the social network analysis

\begin{tabular}{lllllllll}
\hline Group & Nodes & Edges & $\begin{array}{l}\text { Edges } \\
\text { (cognitive) }\end{array}$ & $\begin{array}{l}\text { Edges } \\
\text { (social) }\end{array}$ & $\begin{array}{l}\text { Average } \\
\text { degree }\end{array}$ & Diameter & $\begin{array}{l}\text { Average } \\
\text { path length }\end{array}$ & Density \\
\hline I & 12 & 248 & 163 & 85 & 20.667 & 3 & 1.36 & 0.629 \\
II & 11 & 397 & 115 & 282 & 36.091 & 2 & 1.12 & 0.955 \\
\hline
\end{tabular}



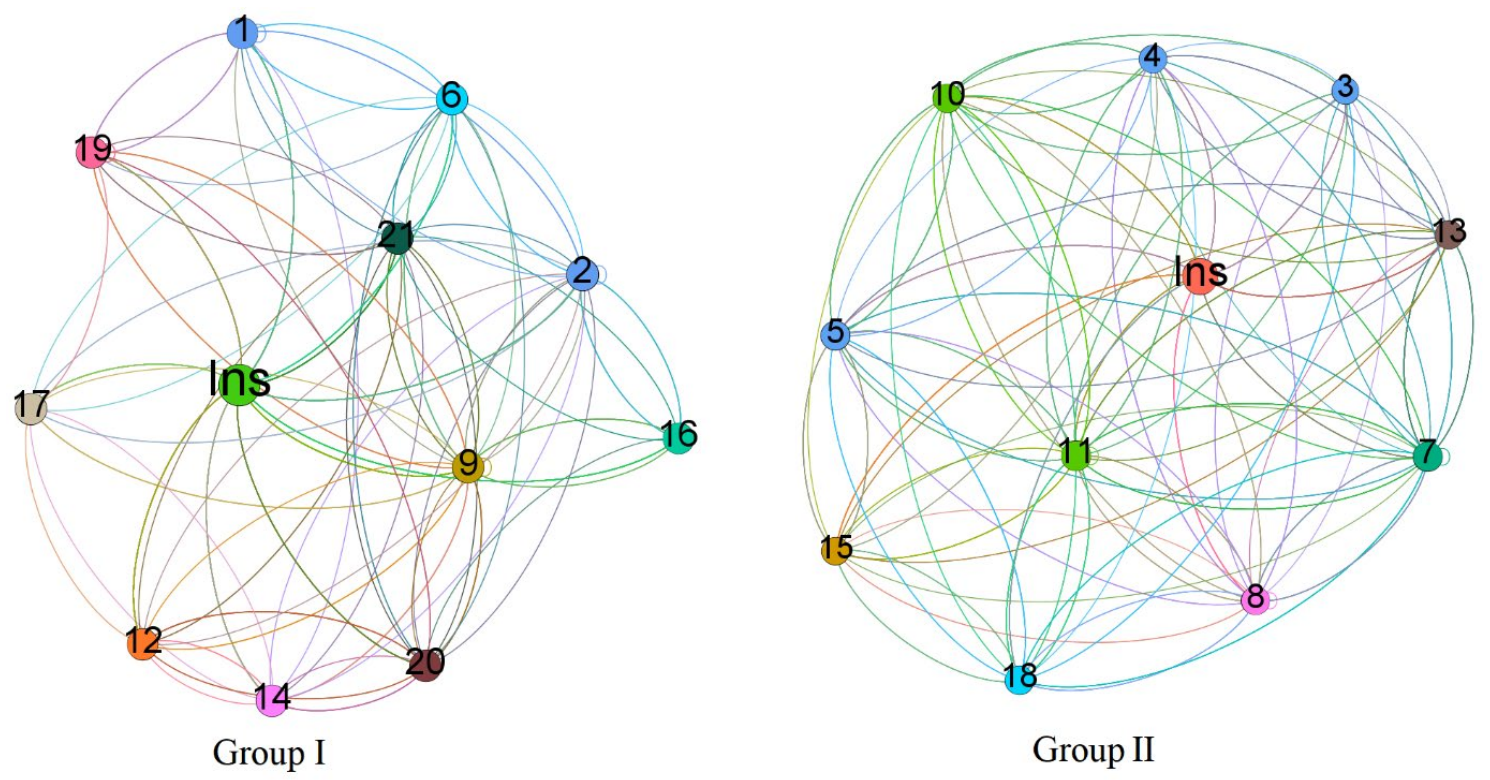

Figure 1. The social networks of the two groups

We explored the number of edges related to both the social and cognitive categories in the two social networks (Table 2). We found that the participants in Group I had more edges related to the cognitive category (i.e., 1.4 times more), whereas Group II had more edges related to the social category (i.e., 3.3 times more). The results showed a higher average number of links per node; that is, each participant in Group II had more communication instances (i.e., sent or received) compared to the participants in Group I. The network diameter was 1.5 times higher in Group I than in Group II. Group I had a 1.2 times longer average path compared to Group II. The results showed that the network density of Group II was 1.5 times higher than that of Group I.

Our results related to the participants' perceptions of the usefulness of the social network for cross-cultural learning showed that most of the students had positive perceptions of their social network; they believed that the social network was beneficial for their cross-cultural learning. There were no significant differences between the perceptions of Group I $(M=4.30 ; S D=0.53)$ and Group II $(M=4.12 ; S D=0.65), t=1.185$, $p=0.241$. In addition, the perceptions of the students did not correlate with learning outcomes, $p>0.5$.

The results of the cultural construct measurements are presented in Table 3. According to the table, participants 14, 21, 11, and 2 had the highest power distance, whereas participants 4 and 16 had the lowest (the power distance for the former was nearly three times that of the latter). Participants 17, 19, and 10 had the highest level of individualism, and participants 4 and 14 had the lowest level (the level of individualism in the former was nearly double that of the latter). Participants 21, 5, 9, and 20 had higher levels of uncertainty avoidance, whereas participants 2, 11, and 12 had the lowest levels, with the former being nearly one and half times greater than the latter. Participants 11, 14, and 21 had the highest levels of masculinity, and participants 1, 16, and 19 had the lowest, with the former being nearly three times greater than the latter. In terms of the correlation between the cultural constructs and cross-cultural learning, the results of the Pearson correlation were not significant. Therefore, we concluded that there was not a significant correlation between the cultural constructs and cross-cultural learning. 
Table 3

Results related to cultural constructs derived from Hofstede's (1983, 2011) model

\begin{tabular}{|c|c|c|c|c|c|c|c|}
\hline $\begin{array}{l}\text { PN \& } \\
\text { Nationality }\end{array}$ & PD & $\begin{array}{l}\text { PN } \\
\text { Nationality }\end{array}$ & I & $\begin{array}{l}\text { PN \& } \\
\text { Nationality }\end{array}$ & UA & $\begin{array}{l}\text { PN \& } \\
\text { Nationality }\end{array}$ & $\mathrm{M}$ \\
\hline 14 Paraguayan & 4.33 & 17 Mexican & 4.33 & 21 Uzbekistani & 4.00 & 11 Indonesian & 3.25 \\
\hline 21 Uzbekistani & 4.00 & 19 Mongolian & 4.00 & 5 Chinese & 3.67 & 14 Paraguayan & 3.00 \\
\hline 11 Indonesian & 3.67 & 10 Indonesian & 3.67 & 9 Indian & 3.67 & 21 Uzbekistani & 3.00 \\
\hline 2 Chinese & 3.33 & 1 Chinese & 3.33 & 20 Filipino & 3.67 & 6 Burkinabe & 2.75 \\
\hline 5 Chinese & 3.33 & 6 Burkinabe & 3.33 & 13 Vietnamese & 3.33 & 7 Burkinabe & 2.75 \\
\hline 13 Vietnamese & 3.33 & 9 Indian & 3.33 & 14 Paraguayan & 3.33 & 20 Filipino & 2.75 \\
\hline 7 Burkinabe & 3.00 & 13 Vietnamese & 3.33 & 16 Honduran & 3.33 & 9 Indian & 2.50 \\
\hline 9 Indian & 3.00 & 15 Panamanian & 3.33 & 17 Mexican & 3.33 & 5 Chinese & 2.25 \\
\hline 3 Chinese & 2.67 & 20 Filipino & 3.33 & 1 Chinese & 3.00 & 10 Indonesian & 2.25 \\
\hline 19 Mongolian & 2.67 & 5 Chinese & 3.00 & 3 Chinese & 3.00 & 12 Vietnamese & 2.25 \\
\hline 20 Filipino & 2.67 & 8 Indian & 3.00 & 4 Chinese & 3.00 & 13 Vietnamese & 2.25 \\
\hline 10 Indonesian & 2.33 & 7 Burkinabe & 2.67 & 6 Burkinabe & 3.00 & 2 Chinese & 1.75 \\
\hline 12 Vietnamese & 2.33 & 11 Indonesian & 2.67 & 7 Burkinabe & 3.00 & 15 Panamanian & 1.75 \\
\hline 18 Belizean & 2.33 & 12 Vietnamese & 2.67 & 8 Indian & 3.00 & 17 Mexican & 1.75 \\
\hline 1 Chinese & 2.00 & 16 Honduran & 2.67 & 10 Indonesian & 3.00 & 3 Chinese & 1.50 \\
\hline 6 Burkinabe & 2.00 & 21 Uzbekistani & 2.67 & 15 Panamanian & 3.00 & 4 Chinese & 1.25 \\
\hline 8 Indian & 2.00 & 2 Chinese & 2.33 & 18 Belizean & 3.00 & 8 Indian & 1.25 \\
\hline 15 Panamanian & 2.00 & 3 Chinese & 2.33 & 19 Mongolian & 3.00 & 18 Belizean & 1.25 \\
\hline 17 Mexican & 2.00 & 18 Belizean & 2.33 & 2 Chinese & 2.67 & 1 Chinese & 1.00 \\
\hline 4 Chinese & 1.33 & 4 Chinese & 2.00 & 11 Indonesian & 2.67 & 16 Honduran & 1.00 \\
\hline 16 Honduran & 1.00 & 14 Paraguayan & 2.00 & 12 Vietnamese & 2.00 & 19 Mongolian & 1.00 \\
\hline
\end{tabular}

Notes. $\mathrm{PN}=$ participant number; $\mathrm{PD}=$ power distance; $\mathrm{I}=$ individualism; $\mathrm{UA}=$ uncertainty avoidance; $\mathrm{M}$ $=$ masculinity.

\section{Discussion and conclusion}

The results of the cross-cultural learning evaluation showed that the participants had procedural and declarative cross-cultural knowledge. During the interviews, the participants confirmed that the learning activity helped them gain a cross-cultural understanding of foreign traditions/culture and that SELT was useful for their cross-cultural communication and information exchange (see Appendix B). This finding suggests that our learning activity supported by SELT technology was beneficial for cross-cultural learning. Similar results have been reported in other related studies. The participants in Shadiev and Huang (2016) communicated and exchanged culture-related information with each other using SELT technology and reported that their cross-cultural learning was promoted. However, the present study was different from earlier research in that the participants in our study were from multiple nationalities and spoke in multiple languages, whereas the participants in earlier studies comprised only two nationalities (Osman \& Herring, 2007; Shadiev \& Huang, 2016; Viberg \& Grönlund, 2013) or spoke a common language (Çiftçi, 2016; Rienties et al., 2015; Walsh et al., 2011; Yamazaki \& Kayes, 2004).

Based on the results of this study, we suggest that educators and researchers design learning activities in which SELT technology is employed. Participant interaction and information exchange should be the core of learning activities intended to facilitate cross-cultural understanding. SELT technology will support participant interaction and information exchange in the native languages of the participants. The participants will be able to communicate in their mother tongue because SELT will translate their communications into the languages of their foreign interlocutors. In this way, participants who do not speak a common language will mutually understand each other's traditions/cultures (Yamazaki \& Kayes, 2004), and their cultural awareness and behaviour will in turn be expanded (Gudykunst et al., 1988). However, educators and researchers should note that our results relate to 10 specific languages only; thus, they should be generalised with caution. Future studies may consider extending cross-cultural communication among participants to other languages, including those that are rare.

Our results showed that the participants in Group I had better procedural and declarative knowledge compared to those in Group II. The participants in Group I interacted with those members of their group whose tradition and culture they wanted to learn and experience, so the communication was limited to 
discussions of a tradition and culture of interest. However, the participants in Group II interacted with every member of their group, and their interactions were not limited to a tradition and culture they wanted to learn and experience. Therefore, the difference in learning performance can be accounted for by the difference in communication styles across the two groups. The communication style of the participants in Group I was more task-oriented and focused on learning about a foreign tradition and culture of interest; that is, the participants in Group I were more focused on their learning and made obvious progress towards their goals (Noy, 2001). In the interviews, the participants from Group II mentioned that they could have obtained better cross-cultural understanding if their communication had been more focused and less social (see Appendix B). Earlier research has described focused communication as being targeted on getting things done, whereas social communication is described emphasising building and maintaining good interpersonal relationships with others (Gugel, 2017, Iosub et al., 2014; Matveev \& Milter, 2004). Although both communication styles are valid and equally useful ways of interacting (Gugesh \& Rani, 2011), they influence cross-cultural learning differently (Matveev \& Milter, 2004; Ogbu, 1992). Our results confirmed this notion since we found that the participants who were engaged in focused communication outperformed those who were engaged in social communication.

Based on our results, we suggest that educators and researchers design learning activities in which the participants use both communication styles. The participants could socially communicate during the first week of the activity (Gugel, 2017; Misiolek et al., 2012). This would help the participants become acquainted with each other and build social relationships (Gugesh \& Rani, 2011). Once the social relationship is established, and the participants are acquainted with each other, more emphasis could be put on focused communication during the rest of the activity (Iosub et al., 2014; Matveev \& Milter; 2004). In this way, the participants will mostly focus on interacting and exchanging culture-related information and learning a foreign tradition and culture that they are interested in, so their cross-cultural learning will be better facilitated (Ogbu, 1992). Our results should be considered in light of certain limitations. Because our study was short-term, our results related to the influence of communication styles should be taken with caution. In future studies, researchers may want to consider extending the learning activity to a longer period of time and investigating whether communication styles will have different impacts on cross-cultural learning.

The qualitative (i.e., the perception questionnaire) results showed that the participants positively perceived their social network. That is, they believed that the social network was beneficial for their cross-cultural learning. Other related studies also have suggested that social networks are beneficial for cross-cultural learning (McPherson et al., 2001). For example, Rienties et al. (2015) found that the cross-cultural learning of the students under consideration was facilitated because they established a social network and used various social network strategies, such as building bridges to cope with mixed group work. Misiolek et al. (2012) warned that although social communication may seem on the surface to be redundant or even distracting, it has a positive connection with more quality decisions and higher satisfaction after the completion of a task. Nevertheless, our questionnaire results showed that the participants using both communication styles were highly satisfied with their online cross-cultural learning experiences. That is, the participants who engaged in focused communication were also highly satisfied with their cross-cultural learning.

The quantitative results showed that the social network characteristics for Group II were much better as compared to those of Group I. For example, Group II had a higher number of edges compared to Group I. That is, the participants in Group II had higher communication frequency. In addition, Group II had a higher average degree of social networking. In other words, on average, each participant in Group II had a higher number of ties to other participants in the group than was the case for Group I. Chen and Chang (2014) suggested that this characteristic represents the degree of popularity and initiative of the participants in learning environment. The network diameter and average path lengths for Group II were shorter than those for Group I. A short network diameter indicates rapid exchange of information among the participants, and a short average path length facilitates the quick transfer of information (Chen \& Chang, 2014). The density for Group II was higher than that for Group I. Higher density in the network shows how well connected it is. On the other hand, the cross-cultural understanding of Group II in terms of procedural and declarative knowledge was lower than that of Group I.

These findings were supported by the interview results (see Appendix B). All participants admitted in the interviews that their social network helped their cross-cultural learning. Furthermore, the participants in 
Group I mentioned that they interacted with a limited number of participants in their group and that this interaction was mostly for the sake of exchanging culture-related information. On the other hand, the participants in Group II said that they established friendships with many group members and socially communicated on different topics both related and unrelated to the tradition and culture of interest.

Therefore, our findings suggest that a social network is beneficial for cross-cultural learning; however, if participants have focused communication, they will tend to socially interact with only a few members of a group, where communication will be focused on a specific culture they want to share and experience. Thus, their cross-cultural understanding will be better, but their social network will be weaker. However, if participants have more social interaction with members of their group, and their interaction is not strictly focused on a tradition and culture of interest but covers some other unrelated topics as well, their social network will be stronger, but their cross-cultural understanding will be lower.

Based on our results, we suggest that the participants in a cross-cultural learning activity build a social network in which they can have both social- and cognition-related interactions. In general, the participants perceived their social network to be useful with regard to facilitating their cross-cultural learning; therefore, if the learning activity is carried out using social networks, the participants will be motivated to communicate and exchange culture-related information. Our results showed a different impact of communication styles on cross-cultural learning and social networks. These findings should be considered by educators and researchers focused on cross-cultural learning in social networks, specifically in regard to determining how to maintain a balance between communication styles during a given learning activity in order to establish a strong social network and facilitate cross-cultural understanding at the same time. In a future study, we may attempt to use our node attributes and link attributes to build a model like the simulation investigation for empirical network analysis (Zhang, Skryabin, \& Song, 2016) or the exponential random graph model (Raab, Lemaire, \& Provan, 2013) to explain the presence of such links.

We found our results related to cultural constructs to be contradictory to those obtained by Hofstede (1983, 1991, 2001, 2011). In his works, Hofstede ranked representatives of different countries according to power distance, individualism, uncertainty avoidance, and masculinity. Unlike Hofstede's results (1983, 1991, 2001, 2011), our results showed that representatives from the same culture can have both the highest and lowest values for some constructs. For example, participant 2 had the highest power distance, and participant 4 had the lowest power distance; both of these participants were from Taiwan.

Representatives from countries ranked to have the highest values for some constructs by Hofstede (1983, 1991, 2001, 2011) had the lowest values in the present study, and vice versa. For example, Hofstede (1983, 1991, 2001, 2011) ranked Panama and Mexico as the countries with the highest power distance; however, according to our results, participants 15 (from Panama) and 17 (from Mexico) had the lowest power distance. Some other studies have also reported contradictory results. For example, Jacob (2005) found inconsistencies related to some of the constructs. She stated that Hofstede $(1991,2001)$ ranked several countries on individualism as being high; however, cross-cultural management practices used in one of these countries may or may not be appropriate in another of these countries. Viberg and Grönlund (2013) argued that Hofstede's factors could not explain the differences in student attitudes in the chosen sample, and they claimed that Hofstede's $(1983,1991,2001,2011)$ model should be questioned. Given the very small sample size involved in the present study, our unique findings in contradiction to Hofstede (1983, 1991, 2001, 2011) should be treated with caution. Therefore, our findings are worthy of further inquiry.

Another interesting finding is that cultural constructs were not found to have a relationship with crosscultural learning. Perhaps this finding draws on the globalisation that has occurred over the past few decades, where proposed cultural differences related to power distance, individualism, uncertainty avoidance, and masculinity are not the same as they were in the past. Due to modern communication tools, media and travel, cultural ideas, meanings, and values can be transmitted all over the world; therefore, nationalities and cultures have become increasingly interconnected, and people have begun to form shared norms and information. Therefore, if a few decades ago, people of a specific culture had stronger power distance or masculinity, now, it may be lower. That is, people's perceptions related to cultural constructs can be shaped by the globalisation process. Again, we warn that the results of the present study should be treated with caution because of the small sample size, so further investigation is warranted. 


\section{Availability of data and material}

The datasets generated and analysed during the current study are not publicly available but will be provided by the corresponding author on reasonable request.

\section{Funding}

The authors received no financial support for the research, authorship, and publication of this article.

\section{Declaration of conflicting interests}

The authors declare that there are no conflicts of interest.

\section{References}

Adams, M., Rodriguez, S., \& Zimmer, K. (2018). Studying cultural relevance in online courses: A thematic inquiry. Online Learning, 22(4), 361-381. https://doi.org/10.24059/olj.v22i4.1262

Aparicio, M., Bacao, F., \& Oliveira, T. (2016). Cultural impacts on e-learning systems' success. The Internet and Higher Education, 31, 58-70. https://doi.org/10.1016/j.iheduc.2016.06.003

Aronson, E., Wilson, T. D., Akert, R.M., \& Sommers, S. R. (2016). Social psychology. London, United Kingdom: Pearson.

Bozkurt, A., \& Akbulut, Y. (2019). Dropout patterns and cultural context in online networked learning spaces. Open Praxis, 11(1), 41-54. https://doi.org/10.5944/openpraxis.11.1.940

Chen, C. M., \& Chang, C. C. (2014). Mining learning social networks for cooperative learning with appropriate learning partners in a problem-based learning environment. Interactive Learning Environments, 22(1), 97-124. https://doi.org/10.1080/10494820.2011.641677

Çiftçi, E. Y. (2016). A review of research on intercultural learning through computer-based digital technologies. Educational Technology \& Society, 19(2), 313-327. Retrieved from https://www.jstor.org/stable/jeductechsoci.19.2.313

Creswell, J. W. (2014). Educational research: Planning, conducting, and evaluating quantitative. Boston, MA: Pearson Education.

ElShiekh, A. A. A. (2012). Google translate service: Transfer of meaning, distortion or simply a new creation? An investigation into the translation process \& problems at google. English Language and Literature Studies, 2(1), 56-68. https://doi.org/10.5539/ells.v2n1p56

Feld, S. L. (1981). The focused organization of social ties. American Journal of Sociology, 86(5), 10151035. https://doi.org/10.1086/227352

Fountain, A. \& Fountain, C. (2009). A new look at translation: Teaching tools for language and literature. In C. Wilkerson (Ed.), Empowerment through collaboration: Dimension (1-15). Roswell, GA: SCOLT.

Garton, L., Haythornthwaite, C., \& Wellman, B. (1997). Studying online social networks. Journal of Computer-Mediated Communication, 3(1). https://doi.org/10.1111/j.1083-6101.1997.tb00062.x

Gilbert, E., \& Karahalios, K. (2009). Predicting tie strength with social media. In Proceedings of the SIGCHI Conference on Human Factors in Computing Systems (pp. 211-220). New York, NY: ACM. https://doi.org/10.1145/1518701.1518736

Granovetter, M. (1983). The strength of weak ties: A network theory revisited. Sociological Theory, 1, 201-233. https://doi.org/10.2307/202051

Gudykunst, W. B., Ting-Toomey, S., \& Chua, E. (1988). Culture and interpersonal communication. Thousand Oaks, CA: Sage.

Gugel, P. (2017). How cultural differences have impacted virtual team effectiveness: A study of teams from the United States (Doctoral dissertation). Retrieved from ProQuest database. (Accession no. 0686692)

Gugesh, J. N., \& Rani, D. S. S. (2011). Influence of culture in knowledge management on virtual team. International Journal of Management, 2(2), 103-112. Retrieved from http://www.iaeme.com/MasterAdmin/Journal_uploads/IJM/VOLUME_2 ISSUE_2/IJM 02 02 012. pdf

Hermet, M., \& Désilets, A. (2009, June). Using first and second language models to correct preposition errors in second language authoring. In Proceedings of the Fourth Workshop on Innovative Use of 
NLP for Building Educational Applications (pp. 64-72). Stroudsburg, PA: Association for Computational Linguistics. https://doi.org/10.3115/1609843.1609853

Hernández-García, Á., González-González, I., Jiménez-Zarco, A. I., \& Chaparro-Peláez, J. (2015). Applying social learning analytics to message boards in online distance learning: A case study. Computers in Human Behavior, 47, 68-80. https://doi.org/10.1016/j.chb.2014.10.038

Hofstede, G. (1983). The cultural relativity of organizational practices and theories. Journal of International Business Studies, 14(2), 75-89. https://doi.org/10.1057/palgrave.jibs.8490867

Hofstede, G. (1986). Cultural differences in teaching and learning. International Journal of Intercultural Relations, 10(3), 301-320. https://doi.org/10.1016/0147-1767(86)90015-5

Hofstede, G. (1991). Cultures and organizations: Software of the mind. New York, NY: McGraw Hill.

Hofstede, G. (2001). Cultural consequences: Comparing values, behaviors, institutions, and organisations across nations. London, United Kingdom: Sage.

Hofstede, G. (2011). Dimensionalizing cultures: The Hofstede model in context. Online Readings in Psychology and Culture, 2(1). https://doi.org/10.9707/2307-0919.1014

Iosub, D., Laniado, D., Castillo, C., Morell, M. F., \& Kaltenbrunner, A. (2014). Emotions under discussion: Gender, status and communication in online collaboration. PloS One, 9(8), 1-23. https://doi.org/10.1371/journal.pone.0104880

Jacob, N. (2005). Cross-cultural investigations: Emerging concepts. Journal of Organizational Change Management, 18(5), 514-528. https://doi.org/10.1108/09534810510614986

Kuo, T. C. T., Shadiev, R., Hwang, W. Y., \& Chen, N. S. (2012). Effects of applying STR for group learning activities on learning performance in a synchronous cyber classroom. Computers \& Education, 58(1), 600-608. https://doi.org/10.1016/j.compedu.2011.07.018

Lustig, M. W., \& Koester, J. (2010). Intercultural competence: Interpersonal communication across cultures. Boston, MA: Pearson Education.

Matveev, A. V., \& Milter, R. G. (2004). The value of intercultural competence for performance of multicultural teams. Team Performance Management: An International Journal, 10(5/6), 104-111. https://doi.org/10.1108/13527590410556827

McMurray, A.A. (2007). Measuring intercultural sensitivity of international and domestic college students: The impact of international travel (Doctoral dissertation). Retrieved from http://ufdc.ufl.edu/UFE0021239

McPherson, M., Smith-Lovin, L., \& Cook, J. M. (2001). Birds of a feather: Homophily in social networks. Annual Review of Sociology, 27, 415-444. https://doi.org/10.1146/annurev.soc.27.1.415

Misiolek, N., Crowston, K., \& Seymour, J. (2012). Team dynamics in long-standing technologysupported virtual teams. Academy of Management Proceedings, 1, 1-35). https://doi.org/10.5465/AMBPP.2012.13362abstract

Mitchell, K. (2012). A social tool: Why and how ESOL students use Facebook. CALICO, 29(3), 471493. https://doi.org/10.11139/cj.29.3.471-493

Noy, S. (2001). Competing priorities: Retention patterns in the Adult Migrant English Program. Sydney, Australia: National Centre for English Language Teaching and Research.

Ogbu, J. U. (1992). Understanding cultural diversity and learning. Educational Researcher, 21(8), 5-14. https://doi.org/10.3102/0013189X021008005

Osman, G., \& Herring, S. C. (2007). Interaction, facilitation, and deep learning in cross-cultural chat: A case study. The Internet and Higher Education, 10(2), 125-141. https://doi.org/10.1016/j.iheduc.2007.03.004

Raab, J., Lemaire, R. H., \& Provan, K.G. (2013). The configurational approach in organizational network research. In P.C. Fiss, B. Cambré, \& A. Marx (Eds.), Configurational theory and methods in organizational research (pp. 225-253). Bingley, United Kingdom: Emerald.

Ranchal, R., Taber-Doughty, T., Guo, Y., Bain, K., Martin, H., Robinson, J., \& Duerstock, B. (2013). Using speech recognition for real-time captioning and lecture transcription in the classroom. IEEE Transactions on Learning Technologies, 6(4), 299 -311. https://doi.org/10.1109/TLT.2013.21

Rienties, B., Johan, N., \& Jindal-Snape, D. (2015). Bridge building potential in cross-cultural learning: A mixed method study. Asia Pacific Education Review, 16(1) pp. 37-48. https://doi.org/10.1007/s12564-014-9352-7

Ryba, K., McIvor, T., Shakir, M., \& Paez, D. (2006). Liberated learning: analysis of university students' perceptions and experiences with continuous automated speech recognition. e-Journal of Instructional Science and Technology, 9(1), 1-19. Retrieved from https://ascilite.org/archived-journals/ejist/docs/vol9 nol/papers/full papers/ryber mcivor shakir paez.htm 
Shadiev, R., \& Huang, Y. M. (2016). Facilitating cross-cultural understanding with learning activities supported by speech-to-text recognition and computer-aided translation. Computers \& Education, 98, 130-141. https://doi.org/10.1016/j.compedu.2016.03.013

Shadiev, R., Hwang, W.Y., Chen, N. S., \& Huang, Y. M. (2014). Review of speech-to-text recognition technology for enhancing learning. Educational Technology \& Society, 17(4), 65-84. Retrieved from http://www.jstor.org/stable/jeductechsoci.17.4.65

Shadiev, R., \& Sun, A. (2019). Using texts generated by STR and CAT to facilitate student comprehension of lecture content in a foreign language. Journal of Computing in Higher Education. https://doi.org/10.1007/s12528-019-09246-7

Shiraev, E. B., \& Levy, D. (2015). Cross-cultural psychology: Critical thinking and contemporary applications. New York, NY: Routledge. https://doi.org/10.4324/9781315664439

Shrum, W., Cheek, N. H., \& Hunter, S. M. (1988). Friendship in school: Gender and racial homophily. Sociology of Education, 61(4), 227-239. https://doi.org/10.2307/2112441

Strang, K. D. (2010). Multicultural e-education: Student learning style, culture and performance. In S. Holim \& T. T. Kidd (Eds.), Handbook of research on human performance and instructional technology (pp. 392-412). Hershey, PA: IGI Global. https://doi.org/10.4018/978-1-60566-7829.ch024

Tobin, A. (2015). Is Google Translate good enough for commercial websites? A machine translation evaluation of text from English websites into four different languages. Reitaku Review, 21, 94-116. https://doi.org/10.18901/00000616

Uzun, L. (2015). The digital world and the elements in digital communication and FL learning. In M. Khosrow-Pour (Ed.), Encyclopedia of information science and technology (3rd ed., pp. 2106-2113). Hershey, PA: IGI Global. https://doi.org/10.4018/978-1-4666-5888-2.ch203

Viberg, O. \& Grönlund, A.. (2013). Cross-cultural analysis of users' attitudes toward the use of mobile devices in second and foreign language learning in higher education: A case from Sweden and China. Computers \& Education, 69, 169-180. https://doi.org/10.1016/j.compedu.2013.07.014

Walsh, G., Brown, Q., \& Druin, A. (2011). Social networking as a vehicle to foster cross-cultural awareness. In Proceedings of International Conference on Interaction Design \& Children (pp. 209212). New York, NY: ACM. https://doi.org/10.1145/1999030.1999063

Yamazaki, Y., \& Kayes, D. C. (2004). An experiential approach to cross-cultural learning: A review and integration of competencies for successful expatriate adaptation. Academy of Management Learning \& Education, 3(4), 362-379. https://doi.org/10.5465/amle.2004.15112543

Zhang, J., Skryabin, M., \& Song, X. (2016). Understanding the dynamics of MOOC discussion forums with simulation investigation for empirical network analysis (SIENA). Distance Education, 37(3), 270-286. https://doi.org/10.1080/01587919.2016.1226230

Corresponding author: Yueh-Min Huang, huang@mail.ncku.edu.tw

Copyright: Articles published in the Australasian Journal of Educational Technology (AJET) are available under Creative Commons Attribution Non-Commercial No Derivatives Licence (CC BY-NC-ND 4.0). Authors retain copyright in their work and grant AJET right of first publication under CC BY-NC-ND 4.0.

Please cite as: Shadiev, R., \& Huang, Y.-M. (2020). Exploring the influence of technological support, cultural constructs, and social networks on online cross-cultural learning. Australasian Journal of Educational Technology, 36(3), 104-118. https://doi.org/10.14742/ajet.6038 


\section{Appendix A}

Key concepts related to a tradition and related culture

\begin{tabular}{|c|c|c|c|}
\hline $\begin{array}{l}\text { Participant } \\
\text { number }\end{array}$ & Communicated content & Translation & Knowledge \\
\hline \multirow[t]{2}{*}{2} & $\begin{array}{l}\text { 我體驗文化是墨西哥亡靈節。 } \\
\text { 我選擇這個是因為在一些美國電 } \\
\text { 影會看到相關影像 } \\
\text { 但是以一種迷幻的方式呈現, } \\
\text { 有時甚至看起來有點瘋狂,讓人害 } \\
\text { 怕。 } \\
\text { 這個節日非常有趣。在亡靈節,墨 } \\
\text { 西哥人不哭泣,他們開心慶祝。在 } \\
\text { 墨西哥的文化裡,死亡並不是一件 } \\
\text { 悲傷的事,而是一種生命的循環。 } \\
\text { 在這天,墨西哥人慶祝能和過世的 } \\
\text { 親人相聚,並且好好得活著。這個 } \\
\text { 觀念和華人非常不一樣。 }\end{array}$ & $\begin{array}{l}\text { I experience culture is the Mexican } \\
\text { Day of the Dead. } \\
\text { I chose this because I see related } \\
\text { images in some American movies } \\
\text { But in a psychedelic way, } \\
\text { Sometimes it looks crazy and scary. } \\
\text { This festival is very interesting. } \\
\text { During the Day of the Dead, } \\
\text { Mexicans do not cry, and they } \\
\text { celebrate happily. In Mexican } \\
\text { culture, death is not a sad thing but a } \\
\text { cycle of life. On this day, Mexicans } \\
\text { celebrate gathering with their dead } \\
\text { relatives and live well. This concept } \\
\text { is very different from the Chinese. }\end{array}$ & Declarative \\
\hline & $\begin{array}{l}\text { 我畫了一個墨西哥風格的骷髏 } \\
\text { 然後把娃娃打扮成Catrina } \\
\text { 我幫他戴上大大的帽子,並用絲巾 } \\
\text { 當成洋裝 } \\
\text { 在書桌上設立了一個簡單的祭壇 } \\
\text { 將檯燈當作蠟燭,並放上一些甜點 } \\
\text { (像是巧克力和奶茶),還有啤酒 } \\
\text { 雖然看起來很簡陃,但我覺得準備 } \\
\text { 起來非常有趣 }\end{array}$ & $\begin{array}{l}\text { I drew a Mexican-style skull } \\
\text { Then dress up the doll as Catrina } \\
\text { I helped him wear a big hat, and use } \\
\text { silk scarves as a dress } \\
\text { Set up a simple altar on the desk } \\
\text { Think of the lamp as a candle and } \\
\text { put some desserts (like chocolate } \\
\text { and tea) and beer } \\
\text { Although it looks very simple, but I } \\
\text { think it is very interesting to prepare }\end{array}$ & Procedural \\
\hline \multirow[t]{2}{*}{10} & $\begin{array}{l}\text { Usbekistan - "morning pilaf": } \\
\text { Tradisi ini sangat menarik karena } \\
\text { kita harus berkumpul bersama dan } \\
\text { makan bersama di pagi hari. } \\
\text { Tradisi ini diadakan ketika ada } \\
\text { acara khusus pada hari tersebut. } \\
\text { Seperti acara pernikahan, kelahiran, } \\
\text { dan tunangan. }\end{array}$ & $\begin{array}{l}\text { Uzbekistan - "morning pilaf": This } \\
\text { tradition is very interesting because } \\
\text { we have to gather together and eat } \\
\text { together in the morning. } \\
\text { This tradition is held when there is a } \\
\text { special event on that day. Such as } \\
\text { weddings, births, and fiancé. }\end{array}$ & Procedural \\
\hline & $\begin{array}{l}\text { Pemiliki acara akan mengundang } \\
\text { kerabat, keluarga dan yang lainnya } \\
\text { untuk menghadiri tradisi ini. Tradisi } \\
\text { ini dilakukan setelah ibadah pagi } \\
\text { "sabzi tugrar". }\end{array}$ & $\begin{array}{l}\text { The event holder will invite } \\
\text { relatives, family and others to attend } \\
\text { this tradition. } \\
\text { This tradition is done after the } \\
\text { morning worship "sabzi tugrar". }\end{array}$ & Procedural \\
\hline
\end{tabular}




\section{Appendix B}

Example extracts from interviews:

Participant 1: The learning activity was useful because I learned about my partner's culture and tradition.

Participant 2: I do not understand Hindu, in which my partner explained her tradition, so I used SELT, and it helped me comprehend her communicated cultural content.

Participant 3: Sometimes, our communication could go off-topic and take our attention away from the main task. I could have learned more about my partner's culture if we could have more task-focused communication.

Participant 4: My social network was helpful to learn about foreign culture and related traditions. My partner and I mostly discussed information about our own culture. 